\title{
Biokomposit Limbah Plastik Polypropylene Berpenguat Serat Lidah Mertua: Proses Ekstraksi dan Kekuatan Mekanis
}

\author{
IP Lokantara ${ }^{1)}$, NPG Suardana ${ }^{2)}$ \\ ${ }^{1,2)}$ Program Studi Teknik Mesin Fakultas Teknik Universitas Udayana \\ Kampus Bukit Jimbaran, Bali 80362 \\ Email: lokantara@unud.ac.id, npgsuardana@unud.ac.id \\ doi: https://doi.org/10.24843/METTEK.2019.v05.i02.p10
}

\begin{abstract}
Abstrak
Tujuan dari penelitian ini adalah untuk menentukan kekuatan tarik dan kekuatan bending biokomposit limbah plastik polypropylene berpenguat serat lidah mertua. Lidah mertua yang digunakan adalah lidah mertua yang pinggirannya daunnya kuning dengan usia yang seragam. Daun lidah mertua direndam dengan metode water retting selama 7 hari dan proses ekstraksi serat dilakukan secara manual. Polypropylene daur ulang yang digunakan berasal dari limbah plastik minuman gelas. Perlakuan kimia serat lidah mertua dengan konsentrasi $5 \% \mathrm{NaOH}$ dan waktu perendaman 2 jam. Komposit dicetak dengan menggunakan press panas dengan suhu $200^{\circ} \mathrm{C}$ dan waktu penahanan 2 jam. Komposit dilakukan pengujian tarik dengan menggunakan ASTM D-570 dan uji bending dengan ASTM 790-03. Hasil uji tarik menunjukkan bahwa kekuatan tarik tertinggi pada fraksi volume 35\% sebesar 71,606 MPa. Kekuatan tarik meningkat sebesar 28,9\% dari fraksi volume $25 \%$ ke fraksi volume $35 \%$. Hasil uji bending menunjukkan bahwa kekuatan bending tertinggi pada fraksi volume $35 \%$ sebesar 74,55 MPa. Kekuatan bending meningkat sebesar $22,9 \%$ dari fraksi volume $25 \%$ ke fraksi volume $35 \%$. Dengan pengamatan foto mikro SEM, ikatan adhesi antara serat dan matrik terjadi dengan baik pada fraksi volume $35 \%$.
\end{abstract}

Kata kunci: Biokomposit, lidah mertua, polypropylene, ekstraksi serat, kekuatan mekanis

\begin{abstract}
The purpose of this study was to determine the tensile strength and bending strength of lidah mertua fiber reinforced polypropylene. Lidah mertua is used whose leaf margins are yellow with a uniform age. Lidah mertua leaves were soaked by water retting method for 7 days. Fiber is extracted manually by hand. Recycled polypropylene used comes from glass beverage plastic waste. The chemical treatment of lidah mertua fibers $5 \% \mathrm{NaOH}$ and a soaking time of 2 hours. Composites are molded using a hot press with a temperature of $200 \mathrm{oC}$ and a holding time of 2 hours. Composite tensile testing was carried out using ASTM D-570 and bending test with ASTM 790-03. Tensile test results showed that the highest tensile strength at 35\% volume fraction was 71,606 MPa. Tensile strength increased by $28.9 \%$ from $25 \%$ volume fraction to $35 \%$ volume fraction. Bending test results showed that the highest bending strength at 35\% volume fraction was $74.55 \mathrm{MPa}$. The bending strength increased by $22.9 \%$ from the 25\% volume fraction to the $35 \%$ volume fraction. By observing SEM micro photographs, the bond between the fiber and the matrix occurs well at $35 \%$ volume fraction
\end{abstract}

Keywords: Biocomposite, lidah mertua, polypropylene, fiber extraction, tensile strength

\section{PENDAHULUAN}

Dekade ini, sebagian besar industri manufaktur tertarik mengembangkan produk yang ramah lingkungan. Karakteristik produk yang dikembangkan tersebut harus ringan, ketersediannya banyak, mudah terurai di alam, tidak mengandung bahan berbahaya dan tidak 
beracun. Maka dari itu, penggunaan serat alam di industri meningkat dari tahun ke tahun. Keunggulan dari serat alam antara lain mudah diekstraksi, ringan, sumber daya alam yang dapat diperbaharui, terurai di lingkungan,[1] Secara khusus, ada kebutuhan serat alam yang besar di sektor otomotif dimana penggunaan serat alam di body kendaraan akan mengurangi berat kendaraan sehingga berdampak pada efisiensi bahan bakar yang lebih baik tanpa mengorbankan kinerjanya. Telah banyak penelitian yang dilakukan di berbagai serat alam sebagai penguat dalam komposit matriks polimer untuk menggantikan serat sintetis [2-4]. Meskipun serat sintetis memiliki sifat seragam dan tidak terurai selama bertahun-tahun, dan telah banyak digunakan dalam dunia industri, namun memiliki beberapa kekurangan diantaranya; harganya mahal, tidak terurai di alam, konsumsi energi tinggi, yang menyebabkan masalah seperti pencemaran lingkungan, iritasi kulit, dan abrasi peralatan saat pengolahan [5]. Serat alam dari tanaman yang diekstraksi umumnya tumbuh di daerah dan lingkungan yang bervariasi. Kondisi tanah, iklim, umur, bagian tanaman menentukan kandungan unsur kimia dan sifat penting lainnya dari serat [6]. Meski begitu, karakteristik penguat yang paling penting adalah tingkatnya sifat adhesi antara serat dan matriks. Oleh karena itu, perlu untuk mengidentifikasi serat alam baru yang memiliki karakteristik baik tanpa perlakuan kimia tambahan. Beberapa jenis serat alam seperti rumput mendong [7], rumput belulang[8], rumput gajah[9], kulit jagung[10], telah diteliti sebagai penguat komposit polimer [7-10]. Pengisi dari komposit secara umum terbuat dari polimer. Dengan tingkat pencemaran lingkungan yang semakin meningkat, beberapa peneliti telah melakukan pengujian menggunakan limbah plastik polypropylene sebagai matrik komposit [11-12]

Penelitian ini mengeksplorasi proses ekstraksi serat dari lidah mertua, uji tarik dan uji bending. Diteliti juga pengaruh perlakuan kimia serat dan fraksi volume serat terhadap kekuatan tarik dan kekuatan bending komposit polypropylene berpenguat serat lidah mertua.

\section{METODE}

\subsection{Proses Ekstraksi Serat}

Daun lidah mertua yang digunakan adalah jenis lidah mertua yang pinggiran daunnya kuning dan panjang daunnya seragam. Lidah mertua dipetik di kawasan Canggu, Kabupaten Badung. Daun lidah mertua dimemarkan agar daun cepat membusuk sehingga seratnya mudah diekstraksi [13]. Serat direndam dengan proses water retting selama 7 hari dalam ember yang berisi air. Daun yang sudah mengalami water retting dibersihkan secara manual dan dibilas dengan air bersih sehingga diperoleh serat berwarna putih tulang, seperti terlihat pada gambar 1 . Serat kemudian dikering anginkan selama 1 hari, kemudian dimasukkan ke dalam oven dengan suhu $60^{\circ} \mathrm{C}$ sampai kadar airnya stabil. Serat yang sudah kering dimasukkan ke dalam wadah plastik untuk menjaga kelembaban serat tetap stabil.
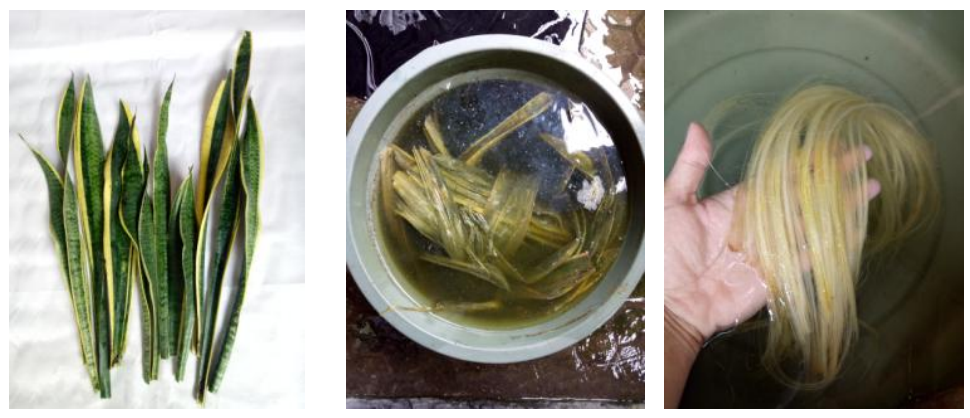


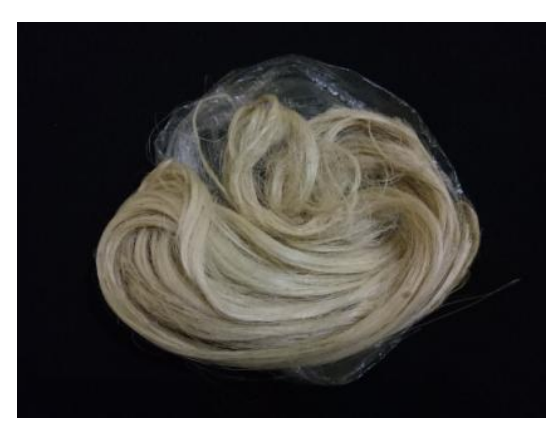

Gambar 1. Proses ekstraksi serat

Plastik yang digunakan adalah jenis polypropylene gelas air mineral seperti pada gambar 2. Gelas plastik dicuci dengan air untuk menghilangkan kotoran yang melekat pada dindingnya. Polypropylene dikering anginkan selama 1 hari, kemudian dipotong kecil-kecil dan selanjutnya disimpan dalam wadah plastik.
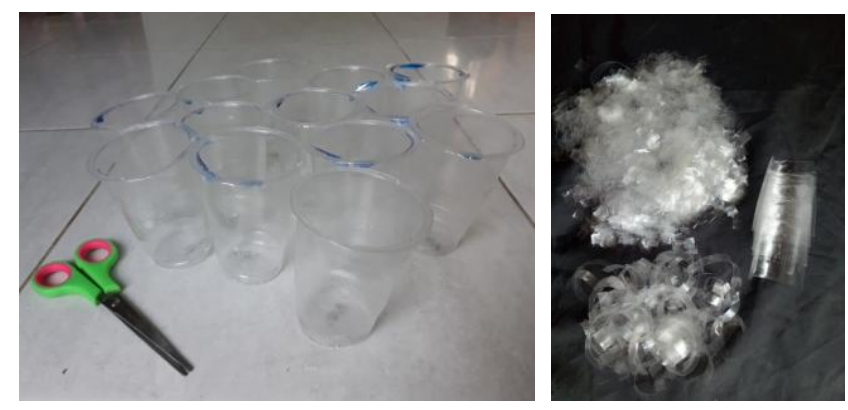

Gambar 2. Plastik polypropylene gelas minuman air mineral

Pada pengujian ini, serat direndam dalam larutan $\mathrm{NaOH} /$ air dengan konsentrasi $5 \%$ berat, selama 120 menit. Selama proses perendaman larutan $\mathrm{NaOH}$ dikondisikan tetap bersirkulasi agar $\mathrm{NaOH}$ tidak mengendap, seperti terlihat pada gambar 3. Setelah proses perendaman, serat dibilas dengan air bersih sampai $\mathrm{pH}$ nya netral. Proses selanjutnya, serat dikeringkan dalam udara terbuka selama 1 hari, kemudian di oven pada suhu $60^{\circ} \mathrm{C}$ sampai kadar airnya stabil. Selanjutnya serat siap digunakan dalam proses pencetakan komposit.

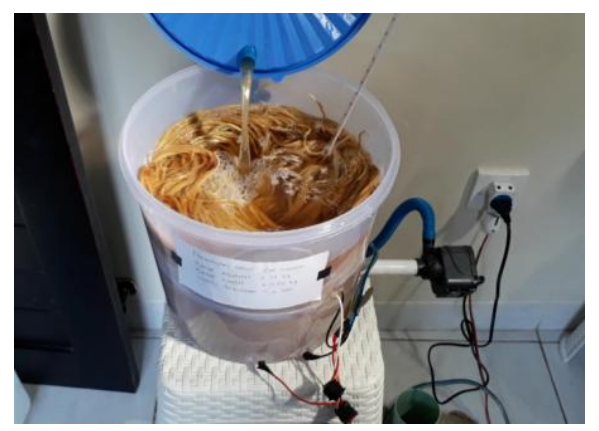

Gambar 3. Proses perendaman serat dalam larutan 5\% NaOH

Pada pengujian ini serat lidah mertua disusun secara berlapis dengan plastik polypropylene. Lapisan dari bawah cetakan ke atas yaitu PP-serat-PP-serat-PP-serat-PP. Serat lidah mertua divariasikan dengan fraksi volume $25 \%, 30 \%, 35 \%$. Komposit dicetak dengan menggunakan metode press panas dengan suhu $170^{\circ} \mathrm{C}$ dengan waktu penahanan selama 2 jam, 
seperti terlihat pada gambar 4 .

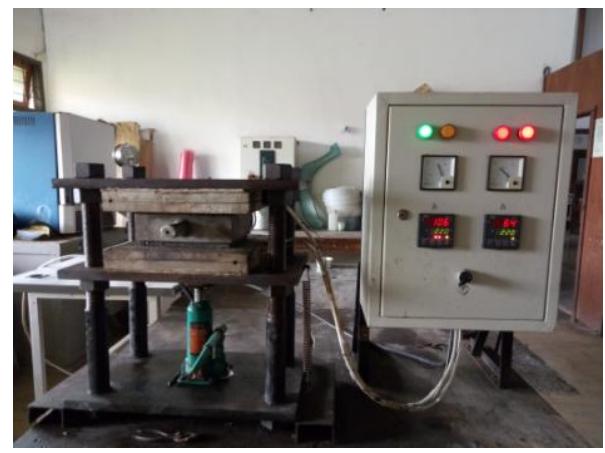

Gambar 4. Mesin press panas

Cetakan komposit yang tanpa perlakuan dan dengan perlakuan $\mathrm{NaOH}$ dipotong menjadi spesimen uji tarik sesuai ASTM D-570 dan uji bending dengan ASTM 790-03. Proses selanjutnya dilakukan pengujian tarik dan pengujian bending.

\subsection{Pengujian Tarik dan Bending}

Pengujian tarik dan bending menggunakan mesin uji Tensilon RTG 1310 dilakukan di Lab Fisika Universitas Mataram, NTB, seperti terlihat pada gambar 5. Spesimen uji tarik dan spesimen uji bending masing-masing fraksi volume sebanyak 3 spesimen. Pengujian dilakukan dengan membandingkan spesimen uji tanpa perlakuan dan yang dengan perlakuan $5 \% \mathrm{NaOH}$.
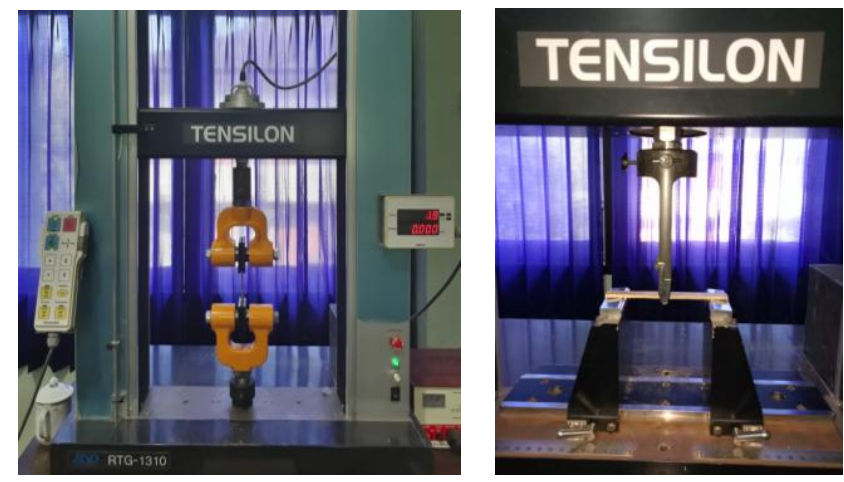

Gambar 5. Mesin uji tarik dan bending

\section{HASIL DAN PEMBAHASAN}

\subsection{Ekstraksi serat lidah mertua}

Daun lidah mertua yang digunakan yaitu daun yang panjangnya sekitar $50 \mathrm{~cm}$. Proses ekstraksi serat yang sesuai yaitu dengan metode water retting, dimana daun lidah mertua direndam dalam wadah ember yang berisi air selama 7 hari. Proses pemilahan serat dilakukan secara manual dengan tangan. Warna dari serat lidah mertua mendekati warna putih tulang.

\subsection{Uji tarik}

Spesimen uji tarik diuji pada kondisi tanpa perlakuan serat dan dengan perlakuan serat menggunakan larutan $\mathrm{NaOH} 5 \%$ selama 2 jam. Pada masing-masing fraksi volume serat dilakukan tiga kali pengulangan. Kondisi pengujian dilakukan pada temperatur kamar dengan kelembaban udara $40 \%$. Hasil pengujian tarik dapat dilihat pada gambar 6 . 
Tabel 1. Tegangan tarik komposit (MPa)

\begin{tabular}{lccc} 
& \multicolumn{3}{c}{ Fraksi volume serat } \\
\cline { 2 - 4 } & $25 \%$ & $30 \%$ & $35 \%$ \\
\hline Tanpa Perlakuan & 32.230 & 40.783 & 48.052 \\
$5 \% \mathrm{NaOH}$ & 55.554 & 61.325 & 71.606 \\
\hline
\end{tabular}

Peningkatan tegangan tarik komposit dengan perlakuan serat dibandingkan dengan tanpa perlakuan serat pada fraksi volume $25 \%, 30 \%, 35 \%$ berturut-turut sebesar 72,3\%, 50,36\%, $49,01 \%$. Pada fraksi volume $25 \%$ pengaruh perlakuan serat dengan $\mathrm{NaOH}$ terlihat paling tinggi, sedangkan pada fraksi volume $30 \%$ dan $35 \%$ peningkatannya hampir sama. Pada fraksi volume 25\%, matrik PP lebih dominan dibandingkan dengan jumlah serat. Ikatan adhesi antara matrik PP dengan serat yang mendapat perlakuan $\mathrm{NaOH}$ lebih baik dibandingkan dengan yang tanpa perlakuan. Matrik mengikat serat dengan baik sehingga transfer tegangan dari matrik ke serat terjadi dengan baik. Pada kondisi tanpa perlakuan serat, lapisan lignin dan lilin pada serat menghambat ikatan adhesi antara serat dengan matrik. Ikatan yang terjadi lebih lemah sehingga tegangan yang terjadi tidak dapat diteruskan dengan sempurna oleh matrik ke serat. Akibatnya dengan pengamatan menggunakan foto SEM seperti pada gambar 7, terlihat bahwa terjadi banyak pull out dan debonding pada permukaan patahan uji tarik.

Tegangan tarik juga meningkat dengan meningkatnya fraksi volume serat. Dari gambar 6, tegangan tarik tertinggi pada fraksi volume $35 \%$ sebesar $71,606 \mathrm{MPa}$, terjadi peningkatan $28,9 \%$ dari fraksi volume $25 \%$ ke fraksi volume serat $35 \%$. Pada fraksi volume $35 \%$, komposisi antara volume serat dan volume matrik PP sangat optimal, matrik membungkus serat dengan sempurna dengan ikatan adhesi yang kuat. Jarak antar serat juga optimal saat matrik meneruskan tegangan yang terjadi oleh gaya luar ke serat. Ikatan adhesi yang baik pada fraksi volume 35\% dapat dilihat pada gambar 7. Patahan serat terlihat lebih merata pada serat dengan perlakuan kimia dibandingkan dengan serat tanpa perlakuan.

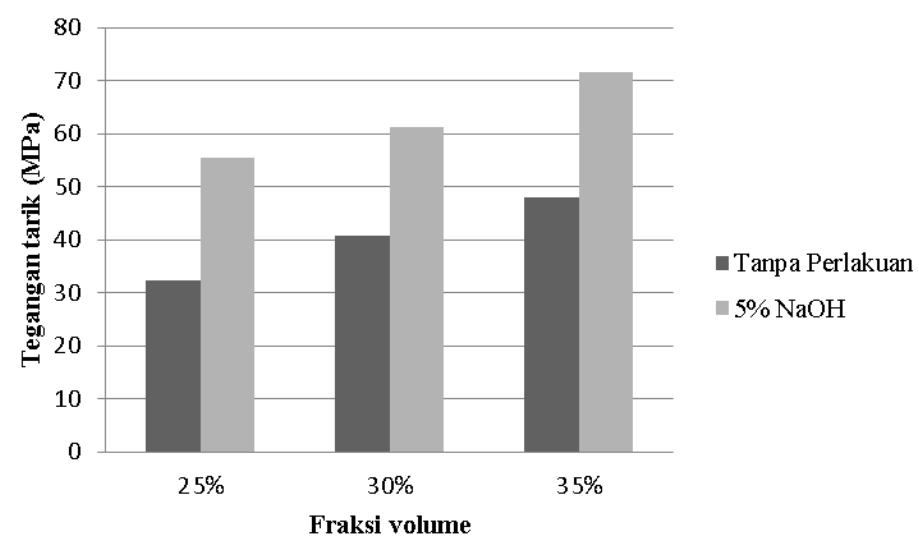

Gambar 6. Variasi fraksi volume serat terhadap tegangan tarik biokomposit 


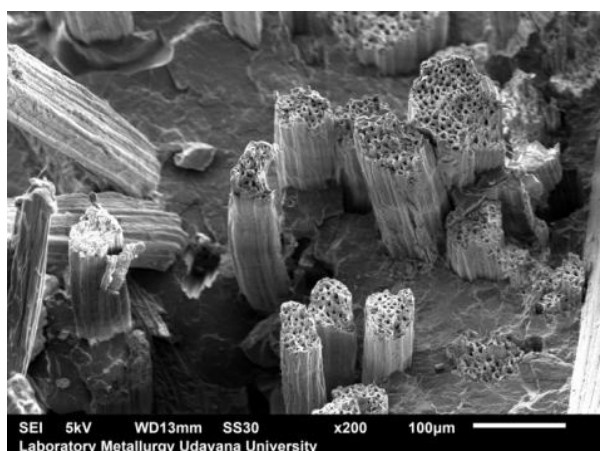

(a)

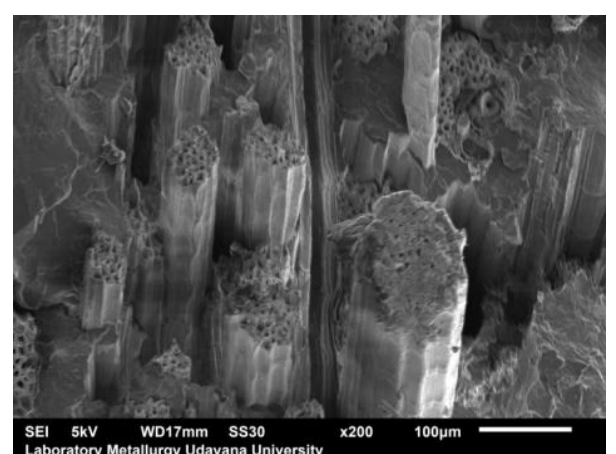

(b)

Gambar 7. Foto SEM (a) tanpa perlakuan (b) $5 \% \mathrm{NaOH}$

\subsection{Uji bending}

Pengujian bending dilakukan pada fraksi volume 25\%, 30\%, 35\% masing-masing dilakukan 3 kali pengulangan. Pengujian juga membandingkan kondisi tanpa perlakuan serat dan dengan perlakuan serat $5 \% \mathrm{NaOH}$ selama 2 jam. Hasil pengujian bending dapat dilihat pada gambar 8 dibawah.

Tabel 2. Tegangan bending komposit (MPa)

\begin{tabular}{lccc} 
& \multicolumn{3}{c}{ Fraksi volume serat } \\
\cline { 2 - 4 } & $25 \%$ & $30 \%$ & $35 \%$ \\
\hline Tanpa Perlakuan & 49.381 & 49.132 & 58.525 \\
$5 \% \mathrm{NaOH}$ & 60.627 & 64.634 & 74.555 \\
\hline
\end{tabular}

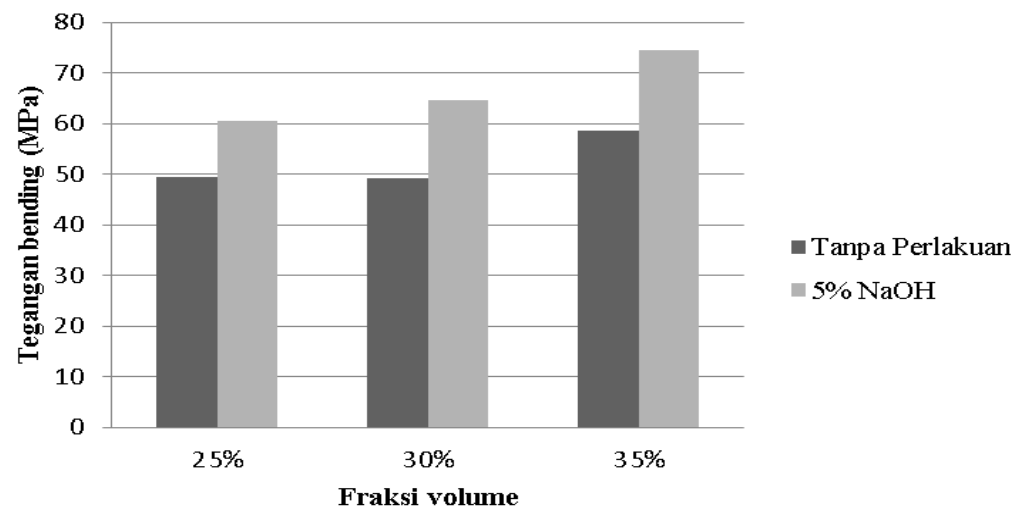

Gambar 8. Variasi fraksi volume serat terhadap tegangan bending biokomposit 


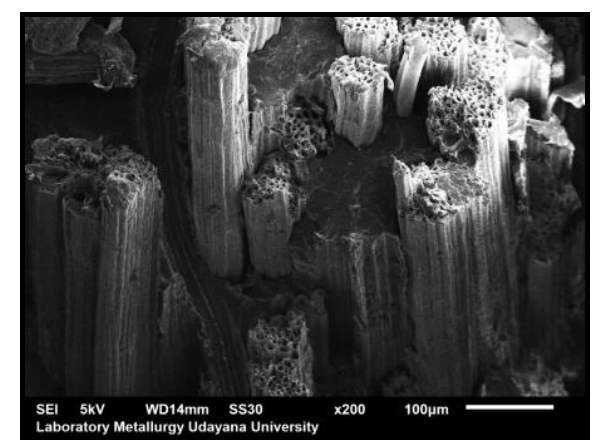

(a)

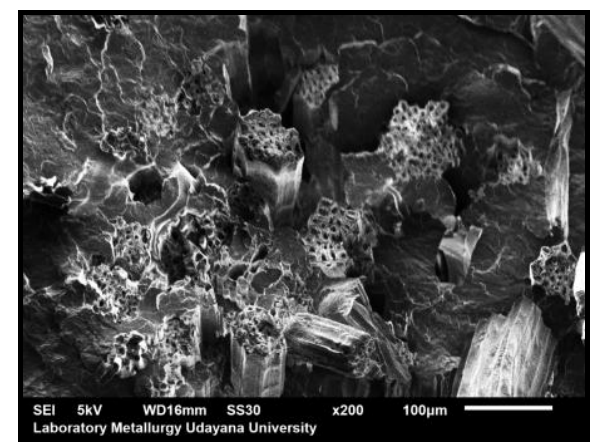

(b)

Gambar 9. Foto SEM (a) tanpa perlakuan (b) $5 \% \mathrm{NaOH}$

Tegangan bending meningkat dengan perlakuan alkali $\mathrm{NaOH}$ dengan rata-rata peningkatan sebesar 27\%. Dari gambar 8, tegangan bending tertinggi pada fraksi volume $35 \%$ sebesar $74,55 \mathrm{MPa}$, terjadi peningkatan $22,97 \%$ dari fraksi volume $25 \%$ ke fraksi volume serat $35 \%$. Jumlah serat dan ikatan adhesi yang baik antara serat dengan matrik menentukan kemampuan lentur komposit dalam menerima tegangan bending. Dengan foto SEM pada gambar 9 sangat terlihat perbedaannya bahwa permukaan patahan serat lebih pendek dan lebih rata dengan perlakuan $\mathrm{NaOH}$ pada serat.

\section{SIMPULAN}

Proses ekstraksi serat lidah mertua menggunakan metode water retting selama 7 hari, pemisahan serat dilakukan secara manual. Tegangan tarik meningkat dengan meningkatnya fraksi volume serat. Tegangan tarik tertinggi pada fraksi volume 35\% sebesar 71,606 MPa, terjadi peningkatan $28,9 \%$ dari fraksi volume $25 \%$ ke fraksi volume serat $35 \%$. Tegangan bending juga meningkat dengan perlakuan alkali $\mathrm{NaOH}$ dan fraksi volume serat. Tegangan bending tertinggi pada fraksi volume $35 \%$ sebesar $74,555 \mathrm{MPa}$, terjadi peningkatan $22,97 \%$ dari fraksi volume $25 \%$ ke fraksi volume serat $35 \%$.

\section{UCAPAN TERIMA KASIH}

Terima kasih kepada Universitas Udayana melalui LPPM yang sudah memberikan dana hibah untuk kelancaran penelitian ini.

\section{DAFTAR PUSTAKA}

[1] Jawaid, M., and H. P. S. Abdul Khalil, Cellulosic/synthetic fiber reinforced: a Review, Carbohydrate Polymer. 86: 1-18, 2011

[2] Senthamaraikannan, P, Saravanakumar. S.S, Arthanarieswaran. V.P and Sugumaran. P, Physicochemical properties of new cellulosic fibers from bark of Acacia planifrons. International Journal of Polymer Analysis and Characterization. 21(3): 207-213, 2016

[3] Mayandi. K, Rajini. N, Pitchipoo. P, Winowlin Jappes. J. T and Varada Rajulu. A, Extraction and characterization of new natural lingo cellulosic fiber Cyperuspangorei. International Journal of Polymer Analysis and Characterization 21: 175-183, 2016

[4] R. Gopinath., K. Ganesan., S.S. Saravanakumar and R. Poopathi, Characterization of new cellulosic fiber from the stem of Sidarhombifolia, International Journal of Polymer Analysis and Characterization, 21(2): 123-129.

[5] Vijay Kumar Thakur., Manju Kumari Thakur and Raju Kumar Gupta, Review: Raw Natural Fiber-Based Polymer Composites, International Journal of Polymer Analysis and Characterization. 19: 256-27, 2014.

[6] C. E. Maepa, J. Jayaramudu, J. O. Okonkwo, S. S. Ray, E. R. Sadiku, and J.Ramontja. Extraction and Characterization of Natural Cellulose Fibers from Maize Tassel. 
International Journal of Polymer Analysis and Characterization, 20: 99-109, 2015

[7] Heru Suryanto, E.M., Yudy Surya Irawan \& Rudy Soenoko, Morphology, Structure, and Mechanical Properties of Natural Cellulose Fiber from Mendong Grass (Fimbristylis globulosa), Journal of Natural Fibers, 11(4): 333-35, 2014

[8] IP Lokantara, NPG Suardana, I Wayan Surata, INS Winaya, The Effect Of Fiber Volume Fraction On Tensile And Impact Properties Of Eleusine Indica Grass Reinforced Polypropylene Bio Composite, International Conference on Design, Energy, Materials and Manufacture IOP Conf. Series: Materials Science and Engineering 539, 2019

[9] Sathishkumar, T.P., Navaneethakrishnan, P., Shankar, S., dan Rajasekar, R, Mechanical properties and water absorption of short snake grass fiber reinforced isophthalic polyester composites, Fibers and Polymers 15(9): 1927-1934, 2014

[10] Sari N H, Wardana I N G, Irawan Y S, Siswanto E, Characterization of the Chemical, Physical, and Mechanical Properties of $\mathrm{NaOH}$-treated Natural Cellulosic Fibers from Corn Husks, Journal of Natural Fibers 15(4) 545-558, 2018

[11] Arun Kumar Gupta, Manoranjan Biswal, S.Mohanty, and S.K.Nayak, Mechanical,Thermal Degradation, and Flammability Studies on Surface Modified Sisal Fiber Reinforced Recycled Polypropylene Composites, Hindawi Publishing Corporation Advances in Mechanical Engineering Volume 2, Article ID 418031, 13 pages, 2012

[12] A.K. Bledzki, P.Franciszczak, Z.Osman, M.Elbadawi, Polypropylene biocomposites reinforced with softwood, abaca, jute and kenaf fiber, Industrial Crops and Products, 70, 91-99, 2015

[13] Rwawiire, S. and B. Tomkova, Morphological thermal and mechanical characterization of sansevieria trifasciata fibers. Journal Of Natural Fibers, no 12, 2015 